Article

\title{
Improving Freedom to Operate in Carrot Breeding through the Development of Eight Open Source Composite Populations of Carrot (Daucus carota L. var. sativus)
}

\author{
Claire H. Luby * and Irwin L. Goldman \\ Department of Horticulture, University of Wisconsin-Madison, 1575 Linden Dr., Madison, WI 53706, USA; \\ ilgoldma@wisc.edu \\ * Correspondence: cluby@wisc.edu; Tel.: +1-608-262-1624
}

Academic Editor: Marc A. Rosen

Received: 15 February 2016; Accepted: 10 May 2016; Published: 14 May 2016

\begin{abstract}
The intellectual property rights (IPR) landscape for plant germplasm has changed dramatically over the past 50 years, moving from the public domain into proprietary structures. Using carrot as a model crop, we explored the freedom to operate for plant breeding and research in relation to the diversity present in 140 commercially available cultivars in the United States. To determine freedom to operate, we characterized the phenotypic and genotypic diversity across cultivars and the IPR that were associated with each cultivar. With 87 of the 95 cultivars that were not restricted by IPR, we developed eight diverse composite populations of carrot through two cycles of breeding that are meant to encompass the available diversity in commercial germplasm. These populations are being released through the Open Source Seed Initiative (OSSI, www.osseeds.org). This is the first example of crop germplasm that has been collected, characterized, and bred specifically for entry into an open source commons.
\end{abstract}

Keywords: carrot; freedom to operate; intellectual property rights; open source; plant breeding

\section{Introduction}

The increase in proprietary protection for crop plants has complicated the exchange of germplasm that is necessary to develop new cultivars through plant breeding. Cultivars used today are continually being selected for adaptation to new diseases and changing environmental conditions. These successes are directly related to the ability of plant breeders and farmers to access diverse plant genetic resources. Over the past 80 years, the freedom to use plant genetic diversity has become complicated by a variety of intellectual property rights (IPR) and international treaties and agreements [1-5]. The practical outcomes of these complications include the inability of plant breeders to obtain seed for breeding or research without entering into contract, license, or material transfer agreements (MTAs) and restrictions on breeding in the form of utility patents and "bag-tag" licenses [6]. As a consequence, breeders may simply choose to avoid using seed from other breeding programs, potentially limiting genetic gain. Collectively, this situation results in a reduction in plant breeders" "freedom to operate" (FTO), or the degree to which intellectual property rights govern the ability to use crop diversity for a specific use or uses. The complications in exchange of germplasm and the reduction in FTO for plant breeding affects how plant breeders are able to use, access and share plant genetic diversity. In this paper, we examine the FTO and IPR landscape in carrot and propose an innovative solution that may hold potential for improving FTO for plant breeders, farmers, gardeners, and seed savers. 


\subsection{Why Carrot?}

We chose to explore FTO in carrot for several reasons. Carrot (Daucus carota var. sativus) is a valuable vegetable crop with 35,000 hectares of carrots produced annually in the U.S., and an annual crop value of $\$ 758 \mathrm{M}$ [7]. It is possible to develop both open-pollinated and $F_{1}$ hybrid cultivars. There are several distinct market classes of carrot based on processing and consumer use, which provide interesting contrasts on the use of IPR. Additionally, both private and public breeding programs exist that release cultivars using a variety of different IPR protections.

Carrot is a biennial, outcrossing diploid in the family Apiaceae. Wild carrot is indigenous to Europe, North Africa, and western Asia with its center of diversity in present day Afghanistan [8]. The first evidence of carrot used as a food crop is in the Iranian plateau (present day Afghanistan, Iran and Pakistan) and the Persian Empire in the 10th century AD [9]. These original domesticated carrots were purple and yellow-rooted [8], meaning that carrots cultivated 900 years ago accumulated anthocyanin compounds in their roots, although we do not know in what concentration. Red-rooted carrots could be found in China and Japan as early as the 1700s [10]. Red-rooted carrots accumulate a large amount of lycopene and $\beta$-carotene $[11,12]$. Orange carrots did not become commonplace until the 17 th century [8].

The majority of breeding over the past 50 years has focused on the development of $F_{1}$ hybrid cultivars, which were largely developed following selection of inbred lines from existing open pollinated cultivars [10]. This is likely because of the ability to utilize heterosis and achieve greater vigor and uniformity. $F_{1}$ hybrids also allow the originator to more easily maintain control of the parent inbred lines. However, there are still many open pollinated carrot cultivars sold by seed companies and in use by gardeners and farmers.

Carrot can be classified into several market classes based on shape and use. We chose to focus on five of these, including: Imperator/Cut-and-Peel/Cello, Nantes, Danvers, Chantenay, and Parissiene/Ball (Figure 1) [10]. Of these, Danvers and Chantenay are typically used for the U.S. canning and freezing markets, while Imperator and Nantes are used for the U.S. fresh market. The Parissiene/Ball type is a novelty fresh market type. While the majority of cultivars are orange-rooted in color, there are also purple, yellow, red and white-rooted carrots that accumulate a variety of secondary compounds, notably carotenoids and anthocyanins.

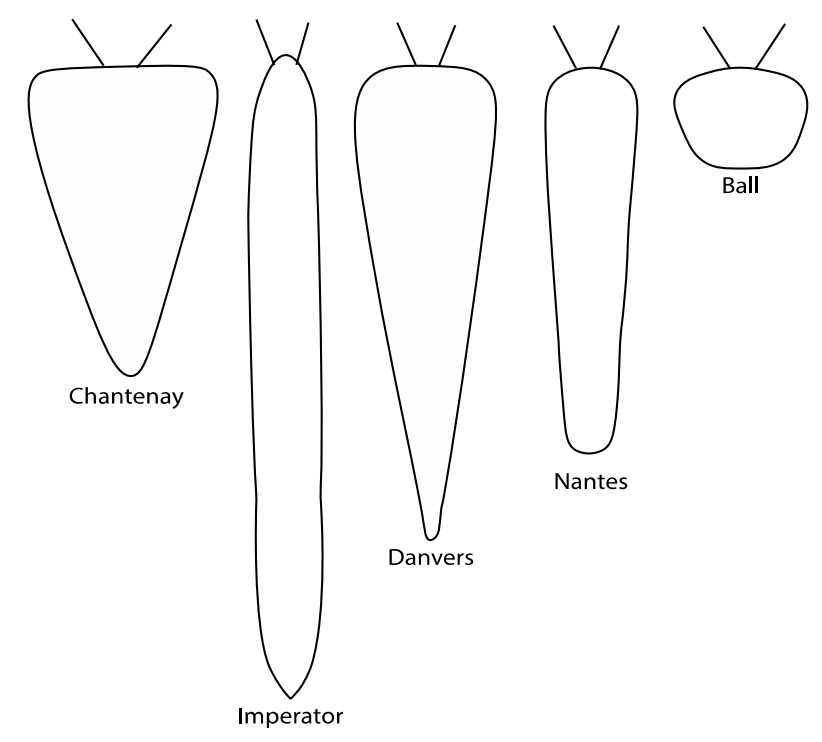

Figure 1. Carrot market classes evaluated for freedom to operate in plant breeding. Chantenay and Danvers are standard processing types in the U.S. Imperator and Nantes are standard fresh market types in the U.S. Parisienne is a novelty fresh market type. 
Both public and private breeding programs exist for carrot and release cultivars in different ways. Historically, $\mathrm{F}_{1}$ hybrids and material transfer agreements (MTAs) were the only mechanisms of protection used in carrot and the majority of material had FTO. The use of other forms of IPR is relatively recent in carrot. These include utility patents, contracts, and "bag-tag" licenses. This transition provides a unique point in history to examine the effect of IPR on FTO in this crop, since there are some cultivars that are protected and some that are still freely available.

\subsection{Intellectual Property Rights for Crop Plant Germplasm}

Over the past 80 years, germplasm has gradually moved from the public domain into more propriety and restricted structures, particularly within the United States $[1-5,13]$. There are many ways that plants can be protected through intellectual property rights in the United States. These include utility patents, plant patents, plant variety protection (PVP), plant breeders' rights (PBR), contract law, trademarks and trade secrets [14]. Of all plant variety rights granted between 1930 and 2008 , including plant patents, plant variety protection certificates (PVP) and utility patents, $42 \%$ were obtained between 2000 and 2008 [15], highlighting the trend toward increasing use of intellectual property rights for plant germplasm. Additionally, the majority of plant variety protections are now from the private sector [15], mirroring the shift from plant breeding as a predominantly public sector activity toward an increase in private sector activity [16]. These trends have implications for how plant germplasm is controlled, distributed and disseminated.

Utility patents are broad forms of IPR protection available through the US Patent and Trademark Office. Inventions must meet strict criteria of novelty, non-obviousness, and utility, and the protection lasts for 20 years. In 2001, the United States Supreme Court case J.E.M. Ag Supply, Inc. v. Pioneer Hi-Bred International, Inc. upheld the Ex parte Hibberd decision by the U.S. Board of Patent Appeals and Interferences in 1985 that plant cultivars and traits were eligible for utility patents $[17,18]$. Since this time, the majority of utility patent applications for crop plants have been for cereal and oilseed crops, which make up $89 \%$ of utility patent applications [15]. However, utility patenting of vegetable crops has increased and make up 5\% of utility patents on plants [15]. Utility patent protection allows owners to exclude others from making, using, or selling the cultivar. Utility patents may also prohibit breeding, seed saving, and even research with the cultivar. Plant patents are also available through the US Patent and Trademark Office but are restricted to asexually reproducing plant species. They last for 20 years and allow the owner to exclude others from propagating, selling, or using the cultivar that is protected.

Plant variety protection is available through the US Department of Agriculture for seed-reproduced crop species. The Plant Variety Protection Act (PVPA) was first introduced in 1970 and was revised in 1980 to include tuber-propagated crops. In order to receive a plant variety protection certificate (PVP), a cultivar must be deemed new, distinct, uniform and stable. The PVPA was developed to provide exclusive rights for 20 years to the breeder of a plant cultivar to control distribution and sale of the cultivar. The PVPA does include three important exemptions that limit the exclusivity and provide some freedom to operate for breeders. These are the "public interest in wide usage exemption", "research exemption", and "farmers seed saving exemption". These exemptions are important as they do allow for the genetic material in a PVP protected cultivar to be used in research and breeding and for farmers to be able to save seed. However, PVP is no longer being used as extensively as it once was. Since 2006, the rate of utility patenting of plant cultivars has outpaced that of PVP applications in all crops [15]. Plant Breeders' Rights provide similar protections as Plant Variety Protection and are of a similar duration, although they require that additional field performance criteria are satisfied. The Plant Variety Protection certificate is actually the US form of Plant Breeders Rights, and many countries have adopted versions of this form of protection for crop cultivars, based on the International Convention for the Protection of new Varieties of Plants (UPOV).

Contract law is increasingly used to protect crop cultivars through the form of licenses and other legal instruments. Contracting parties may specify how the cultivar may be used, bred, sold, 
and marketed under such contracts, as well as the time frame for these protections. Trademarks are available through the US Patent and Trademark Office. A trademark allows the owner to protect the brand name of a cultivar, and can be licensed for use by others, although the cultivar itself may not be trademarked. This may allow licensors to specify how a cultivar can be used, propagated, marketed, and sold. Trade secrets are practices or methods used by companies that are not publicly known and may be used to gain an advantage over others in the same area of commerce. The development of proprietary inbred parent lines might constitute a trade secret that the developer can use to retain an advantage over competitors. While the $\mathrm{F}_{1}$ hybrid produced from these proprietary inbred parental lines may be released without IPR, the trade secret protection inherent in the parent lines provides a sort of built-in biological protection for the $\mathrm{F}_{1}$ hybrid.

\section{Experimental Section}

\subsection{Population Development}

In order to determine the FTO landscape for plant breeding with carrot cultivars, we documented what types of IPR were associated with each cultivar and whether the cultivar had FTO. Additionally, we characterized the phenotypic and genotypic diversity present in commercially available carrot cultivars. Using the cultivars that had FTO for plant breeding, we developed eight diverse composite populations of carrot that are meant to represent the available diversity [19]. The populations are being released under the Open Source Seed Initiative (OSSI) Pledge in order to ensure at least a portion of the diversity represented by these cultivars has FTO for plant breeding into the future. In this paper, we discuss the process of determining freedom to operate with commercially available carrot germplasm and the subsequent development of eight pre-breeding composite populations of carrot.

Through consultation with carrot breeders in the public and private sectors as well as through seed catalogs, we were able to obtain seed of $140 \mathrm{~F}_{1}$ hybrid, open-pollinated and heirloom carrot cultivars that were commercially available in the United States in 2013. All cultivars were grown in replicated plots $3.7 \mathrm{~m}$ in length on certified organic land at Tipi Organic Produce in Evansville, WI $\left(42.78^{\circ} \mathrm{N}, 89.30^{\circ} \mathrm{W}\right)$ and Elderberry Hill Farm in Waunakee, WI $\left(43.18^{\circ} \mathrm{N}, 89.38^{\circ} \mathrm{W}\right)$ in the summers of 2013 and 2014. For each cultivar, roots were phenotyped and categorized based on root shape and color. We also determined whether FTO was present or absent based on the intellectual property rights and ownership associated with each cultivar. This included noting whether the cultivar was protected by contract, "bag tag" license, MTA, PVP, or utility patent. Some of the cultivars were not attributed to a particular market class and we assigned them to market class categories following phenotypic evaluations.

Using the roots grown in 2013 for which we had FTO, we developed eight diverse composite populations based on root color and market class in the greenhouse during the winter of 2013-2014 [19]. Roots from each cultivar with FTO were separated from tops, trimmed, and vernalized at $4{ }^{\circ} \mathrm{C}$ for 10 weeks; $7-10$ roots of each cultivar were planted in pots in the greenhouse in December and grown in a $16 \mathrm{hr}$ photoperiod at $20^{\circ} \mathrm{C}$. Roots were separated according to market class categories and colors and grouped accordingly for crossing in insect-proof netted cages. Accounting for losses due to rot or plant death, each cage had between 20 and 60 roots and 3 to 19 cultivars contributing to the next generation, depending on the population [19]. When the primary umbels began to open, house fly pupae (Musca domestica) were placed in each cage at weekly intervals for six weeks. Flowering was not completely synchronous among all plants in each cage. However, since plants produce 3-5 umbels, a window of time where cross-pollination could occur was achieved in all cages. At seed maturity, seeds were harvested from each plant separately, and an equal amount of seed from each plant was combined for each population, creating a balanced bulk of seed of the populations we designated the "composite 1 generation". Collectively, the populations comprise the Wisconsin Open Source Composite (WI-OSC) collection. The market class populations were classified as "WI-OSC Nantes", "WI-OSC Danvers", "WI-OSC Chantenay", "WI-OSC Ball", and are meant to represent those root 
shapes (Figure 2). The root color populations are "WI-OSC Red", "WI-OSC Purple", "WI-OSC White", and "WI-OSC Yellow" (Figure 2).

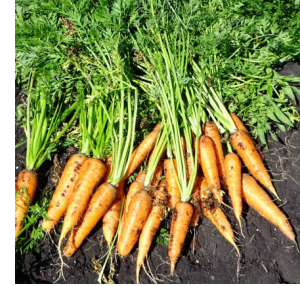

WI-OSC Danvers

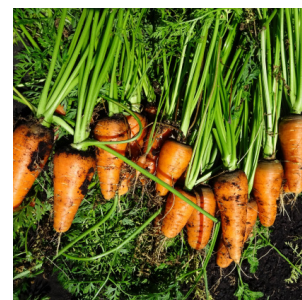

WI-OSC Chantenay

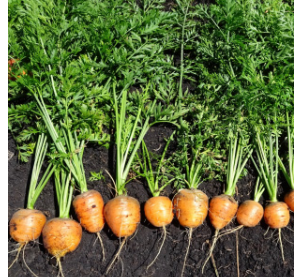

WI-OSC Ball

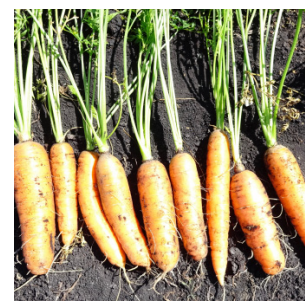

WI-OSC Nantes

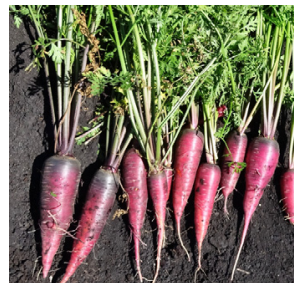

WI-OSC Purple

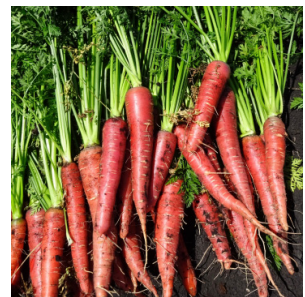

WI-OSC Red

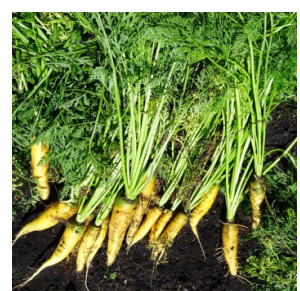

WI-OSC Yellow

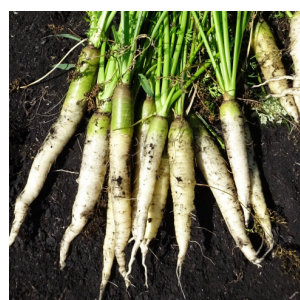

WI-OSC White

Figure 2. Wisconsin Open Source Composite populations released under the Open Source Seed Initiative. Clockwise from upper left, Danvers, Ball, Purple, Yellow, White, Red, Nantes, and Chantenay.

Seeds of each composite 1 population were sown in replicated plots at Tipi Organic Produce in Evansville, WI in June 2014. All roots from these plots were harvested in October and stored at $4{ }^{\circ} \mathrm{C}$ for 24 weeks. Roots were transplanted to cages in the field at Tipi Organic Produce in April 2015. When the primary umbels opened, Blue Bottle fly pupae (Diptera calliphoridae) were introduced into each cage at weekly intervals for six weeks. When seed was mature, it was harvested and a bulk of seed was produced for each composite 2 population. These composite 2 populations were released through the OSSI Pledge.

\subsection{Determining $F T O$}

Determining FTO and the IPR associated with each cultivar was not always obvious or straightforward. For the purposes of our project, FTO was either present or absent, though of course it is possible to have gradations of freedom to use a particular seed source. For example, the ability to use germplasm is often accompanied by an MTA or license outlining royalty arrangements for any commercial developments. However, for many public plant breeding programs, any restriction on FTO would translate into limited or "no use" of a particular seed source in a breeding program. There are cases where terms of use are explicitly laid out such as contracts detailing exactly how seed can be used. In other cases, limitations are vague or implied but not explicit such as "bag tag" licenses, precluding the use of germplasm since FTO is unclear. When determining what cultivars were available to use in breeding, we first noted what type of IPR was associated with each cultivar. We did not use those that had explicit restrictions on breeding. However, there were many cultivars where it was unclear exactly whether there was a use-restriction on breeding. These included cultivars with some form of "bag tag" license and cultivars that were obtained from a breeder where it was unknown whether the parent company would agree to allow a cultivar to be used in breeding without some type of exclusive contract. Additionally, there were several cultivars with use-restrictions when they were obtained from one company, but that did not appear to have the same use-restrictions when seed of the same cultivars were obtained from a different company. We did not include those cultivars in our composite populations due to this discrepancy. This example emphasizes both the difficulty in retaining control of seed by the company through the use of IPR and in determining FTO for plant breeding for a given cultivar. 
While the majority of cultivars did not have formal restrictions on use, the various types of IPR and the uncertainty surrounding FTO did determine whether we chose to include a cultivar in breeding. When it was unclear what the extent of a restriction was, we did not include the cultivar in the assembly of the populations, as we only wanted to use material that was explicitly available to use in breeding.

\subsection{Special Considerations}

While the goal of many breeding programs is to develop cultivars or inbred lines that are genetically stable and homogenous, the goal here was to develop populations that represent some of the available diversity in commercial carrot cultivars that can be used as pre-breeding populations with FTO. Thus they are intentionally diverse. We included $\mathrm{F}_{1}$ hybrids that had FTO in these populations. The cytoplasmic male sterility system is used to create $\mathrm{F}_{1}$ hybrid cultivars in carrot and it is also found at varying frequencies in open pollinated cultivars of carrot. As a result, sterile cytoplasm existed in the source material for these composite populations and is found to varying degrees in the populations. However, we wanted to ensure that the diversity represented by these cultivars was included in the populations.

The organic sector was a consideration throughout the process of developing these carrot populations. We obtained organic seed where possible. Of the 140 cultivars obtained for this study, only 24 were available as organically produced seed. Trialing was conducted on organically certified land, thus we only used untreated seed of the cultivars where organic seed was not available. These populations might therefore be considered pre-breeding populations that have FTO for development of new cultivars for organic systems.

\section{Results and Discussion}

Due to the presence of IPR, not all commercial cultivars are available for breeding. Plant breeders must therefore evaluate IPR when determining whether FTO exists for breeding with specific material. We determined FTO for a collection of 145 carrot cultivars. Our primary finding was that the process of assessing FTO is cumbersome and that both ownership and IPR of most cultivars is often ambiguous. This can create a chilling effect on the use of cultivars in breeding and a degree of legal uncertainty with respect to the downstream implications of using cultivars whose FTO is unclear.

We initially determined that 172 carrot cultivars were commercially available in the U.S. in 2013. We were able to obtain seed of 145 of these cultivars. We could not obtain seed of 27 cultivars for a variety of reasons. For some, there had been a seed crop failure or seed was out of stock and thus unavailable. Others were identified as available but when we requested seed from the company, we did not receive seed of all cultivars. The reasons for this were not determined. Although we received seed of 145 cultivars, we planted seed of only 140. Five cultivars were only available with chemically-treated seed. Since our trials were on certified organic farms, we were not able to include these cultivars in the study.

Of the 140 cultivars that were planted, ten market classes and five color classes were represented; 77 cultivars were $\mathrm{F}_{1}$ hybrids. Table 1 outlines the cultivars that we obtained, the company where they were obtained from, and the market class, color class, type and FTO for each. Of the 140 that were obtained, we determined that 95 had FTO for plant breeding. We used 87 cultivars in compiling the composite populations. Eight of the 95 were not used because there were limited numbers of cultivars with FTO for a particular market class. For example, the majority of imperator-classified cultivars were not available to use (4 out of the 30 orange rooted cultivars had FTO), thus we did not develop an imperator population. Interestingly, this market class has been the focus of most US based breeding programs [10] and is the one most likely to have the greatest level of market competition for cultivars. We also decided not to make composite populations of the Berlicum, Kuroda, Amsterdam Forcing, or Flakee type roots, as these are not commonly grown market classes in the U.S. and there were not many cultivars included in the trial that were classified under these market classes. The following 
describes each type of IPR that was present for commercially available carrots in the U.S. and the impact that this had on our decision-making process for determining FTO.

Table 1. A total of 140 carrot cultivars were commercially available in 2013 . This table includes the company where seed was obtained from, the freedom to operate for plant breeding ( $\mathrm{n}=$ no FTO, $\mathrm{y}=$ has FTO), the color ( $\mathrm{o}=$ orange, $\mathrm{p}=$ purple, $\mathrm{r}=$ red, $\mathrm{y}=$ yellow, $\mathrm{w}=$ white), type $(\mathrm{H}=\mathrm{F} 1$ hybrid, $\mathrm{OP}=$ open pollinated), and market class.

\begin{tabular}{|c|c|c|c|c|c|}
\hline Cultivar & Company & FTO & Color & Type & Market Class \\
\hline Abledo & Seminis & $\mathrm{n}$ & o & $\mathrm{H}$ & Chantenay \\
\hline Achieve & Seminis & $\mathrm{n}$ & o & $\mathrm{H}$ & Flakee \\
\hline Adelaide baby & Kitchen Garden Seeds & $\mathrm{y}$ & o & $\mathrm{H}$ & Amsterdam \\
\hline Amarillo & Baker Creek & $\mathrm{y}$ & $\mathrm{y}$ & $\mathrm{OP}$ & Danvers \\
\hline Amsterdam 2 & Fedco & $\mathrm{y}$ & $\mathrm{o}$ & $\mathrm{OP}$ & Amsterdam \\
\hline Apache & Nunhems & $\mathrm{n}$ & o & $\mathrm{H}$ & Imperator \\
\hline Arrowhead & Sakata & $\mathrm{n}$ & o & $\mathrm{H}$ & Imperator \\
\hline Atlas & Johnny's & $\mathrm{y}$ & o & $\mathrm{OP}$ & Ball \\
\hline Atomic red & High Mowing & $\mathrm{y}$ & $\mathrm{r}$ & $\mathrm{OP}$ & Danvers \\
\hline Autumn King & Annie's Heirloom Seeds & $\mathrm{y}$ & $\mathrm{o}$ & $\mathrm{OP}$ & Nantes \\
\hline Baby Babette & Renee's Garden Seeds & $\mathrm{y}$ & o & $\mathrm{H}$ & Nantes \\
\hline Baltimore & Vermont Bean Seed Company & $\mathrm{y}$ & o & $\mathrm{H}$ & Belgian \\
\hline Bambino & Sustainable Seed & $\mathrm{y}$ & o & $\mathrm{OP}$ & Amsterdam \\
\hline Bastia & Bejo & $\mathrm{n}$ & o & $\mathrm{H}$ & Belgian \\
\hline Berlicum 2 & Baker Creek & $\mathrm{y}$ & $\mathrm{o}$ & $\mathrm{OP}$ & Berlicum \\
\hline Big Sur & Nunhems & $\mathrm{n}$ & o & $\mathrm{H}$ & Danvers \\
\hline Big Top & Burpee & $\mathrm{y}$ & $\mathrm{o}$ & $\mathrm{H}$ & Chantenay \\
\hline Bilbo & Veseys & $\mathrm{y}$ & $\mathrm{o}$ & $\mathrm{H}$ & Nantes \\
\hline Bolero & Johnny's & $\mathrm{y}$ & $\mathrm{o}$ & $\mathrm{H}$ & Nantes \\
\hline Brilliance & Reimer Seeds & $\mathrm{y}$ & o & $\mathrm{OP}$ & Nantes \\
\hline Burpee A1 & Burpee & $\mathrm{y}$ & o & $\mathrm{H}$ & Imperator \\
\hline Candysnax & Nunhems & $\mathrm{n}$ & $\mathrm{o}$ & $\mathrm{H}$ & Imperator \\
\hline Caracas & Johnny's & $\mathrm{y}$ & o & $\mathrm{H}$ & Chantenay \\
\hline Carson & Bejo & $\mathrm{n}$ & o & $\mathrm{H}$ & Chantenay \\
\hline Cellobunch & Seminis & $\mathrm{n}$ & $\mathrm{o}$ & $\mathrm{H}$ & Imperator \\
\hline Chantenay Royal & Reimer Seeds & $\mathrm{y}$ & o & $\mathrm{OP}$ & Chantenay \\
\hline Choctaw & Nunhems & $\mathrm{n}$ & o & $\mathrm{H}$ & Imperator \\
\hline Coral II & Evergreen Seeds & $\mathrm{y}$ & o & $\mathrm{H}$ & Chantenay \\
\hline Cosmic Purple & High Mowing & $\mathrm{y}$ & $\mathrm{p}$ & $\mathrm{OP}$ & Danvers \\
\hline Creampak & Nunhems & $\mathrm{n}$ & w & $\mathrm{H}$ & Imperator \\
\hline Crème de Lite & Nunhems & $\mathrm{n}$ & $\mathrm{w}$ & $\mathrm{H}$ & Danvers \\
\hline Crispy Cut & Nunhems & $\mathrm{n}$ & o & $\mathrm{H}$ & Imperator \\
\hline Cumbre & Nunhems & $\mathrm{n}$ & o & $\mathrm{H}$ & Chantenay \\
\hline Cupar & Bejo & $\mathrm{n}$ & o & $\mathrm{H}$ & Chantenay \\
\hline Damco & Osbourne Seed & $\mathrm{y}$ & $\mathrm{o}$ & $\mathrm{H}$ & Amsterdam \\
\hline Danvers 126 Half-long & Burpee & $\mathrm{y}$ & o & $\mathrm{OP}$ & Danvers \\
\hline Danvers 126 & High Mowing & $\mathrm{y}$ & o & $\mathrm{OP}$ & Danvers \\
\hline Deep Purple & Johnny's & $\mathrm{y}$ & $\mathrm{p}$ & $\mathrm{H}$ & Danvers \\
\hline Dominion & Seminis & $\mathrm{n}$ & o & $\mathrm{H}$ & Belgian \\
\hline Dragon & High Mowing & $\mathrm{y}$ & $\mathrm{p}$ & $\mathrm{OP}$ & Danvers \\
\hline Early Milan Nantes & Turtle Tree & $\mathrm{y}$ & o & $\mathrm{OP}$ & Nantes \\
\hline Envy & Seminis & $\mathrm{n}$ & o & $\mathrm{H}$ & Danvers \\
\hline Flakkee & Reimer Seeds & $\mathrm{y}$ & o & $\mathrm{OP}$ & Flakee \\
\hline Flyaway & Osbourne Seed & $\mathrm{y}$ & o & $\mathrm{H}$ & Nantes \\
\hline Hilmar & Osbourne Seed & $\mathrm{y}$ & o & $\mathrm{OP}$ & Danvers \\
\hline HoneySnax & Nunhems & $\mathrm{n}$ & o & $\mathrm{H}$ & Imperator \\
\hline Imperator 58 & Reimer Seeds & $\mathrm{y}$ & o & $\mathrm{OP}$ & Imperator \\
\hline Ingot & Sakata & $\mathrm{n}$ & o & $\mathrm{H}$ & Nantes \\
\hline Interceptor & High Mowing & $\mathrm{y}$ & o & $\mathrm{H}$ & Imperator \\
\hline Inverness & Kitchen Garden Seeds & $\mathrm{y}$ & o & $\mathrm{H}$ & Imperator \\
\hline Invicta & Osbourne Seed & $\mathrm{y}$ & o & $\mathrm{H}$ & Nantes \\
\hline James Scarlet & Reimer Seeds & $\mathrm{y}$ & o & $\mathrm{OP}$ & Danvers \\
\hline Jaune du Doubs & Fedco & $\mathrm{y}$ & o & $\mathrm{OP}$ & Danvers \\
\hline Jeannette & High Mowing & $\mathrm{y}$ & o & $\mathrm{H}$ & Nantes \\
\hline Jerada & Osbourne Seed & $\mathrm{y}$ & $\mathrm{o}$ & $\mathrm{H}$ & Nantes \\
\hline Juwarot & Bountiful Gardens & $\mathrm{y}$ & o & $\mathrm{OP}$ & Danvers \\
\hline
\end{tabular}


Table 1. Cont.

\begin{tabular}{|c|c|c|c|c|c|}
\hline Cultivar & Company & FTO & Color & Type & Market Class \\
\hline King Midas & Renee's Garden Seeds & $\mathrm{y}$ & o & $\mathrm{OP}$ & Danvers \\
\hline Kuroda Long & Reimer Seeds & $\mathrm{y}$ & o & $\mathrm{OP}$ & Kuroda \\
\hline Kuroda Nova & West Coast Seeds & $\mathrm{y}$ & $\mathrm{o}$ & $\mathrm{OP}$ & Kuroda \\
\hline Laguna & Nunhems & $\mathrm{n}$ & o & $\mathrm{H}$ & Nantes \\
\hline Legend & Seminis & $\mathrm{n}$ & $\mathrm{o}$ & $\mathrm{H}$ & Danvers \\
\hline Little Finger & Baker Creek & $\mathrm{y}$ & o & $\mathrm{OP}$ & Amsterdam \\
\hline Lunar White & Baker Creek & $\mathrm{y}$ & $\mathrm{w}$ & $\mathrm{OP}$ & Belgian \\
\hline Maverick & Nunhems & $\mathrm{n}$ & o & $\mathrm{H}$ & Imperator \\
\hline Mellow Yellow & Bejo & $\mathrm{n}$ & $\mathrm{y}$ & $\mathrm{H}$ & Danvers \\
\hline Merida & Osbourne Seed & $\mathrm{y}$ & $\mathrm{o}$ & $\mathrm{H}$ & Nantes \\
\hline Mignon & West Coast Seeds & $\mathrm{y}$ & o & $\mathrm{OP}$ & Amsterdam \\
\hline Mini Sweet & Bountiful Gardens & $\mathrm{y}$ & o & $\mathrm{OP}$ & Amsterdam \\
\hline Minicor & Turtle Tree & $\mathrm{y}$ & $\mathrm{o}$ & $\mathrm{OP}$ & Nantes \\
\hline Mokum & Bejo & $\mathrm{n}$ & $\mathrm{O}$ & $\mathrm{H}$ & Nantes \\
\hline Muscade & Baker Creek & $\mathrm{y}$ & $\mathrm{o}$ & $\mathrm{OP}$ & Danvers \\
\hline Nantes Half-long & Burpee & $\mathrm{y}$ & $\mathrm{o}$ & $\mathrm{OP}$ & Nantes \\
\hline Nantes Mini-core & Reimer Seeds & $\mathrm{y}$ & $\mathrm{o}$ & $\mathrm{OP}$ & Nantes \\
\hline Nantindo & Osbourne Seed & $\mathrm{y}$ & $\mathrm{o}$ & $\mathrm{H}$ & Nantes \\
\hline Napa & Bejo & $\mathrm{n}$ & $\mathrm{O}$ & $\mathrm{H}$ & Nantes \\
\hline Napoli & Bejo & $\mathrm{n}$ & $\mathrm{o}$ & $\mathrm{H}$ & Nantes \\
\hline Nash's Nantes & Nash Huber & $\mathrm{y}$ & $\mathrm{o}$ & $\mathrm{OP}$ & Nantes \\
\hline Necoras & High Mowing & $\mathrm{n}$ & $\mathrm{o}$ & $\mathrm{H}$ & Nantes \\
\hline Nectar & Johnny's & $\mathrm{n}$ & $\mathrm{o}$ & $\mathrm{H}$ & Nantes \\
\hline Negovia & High Mowing & $\mathrm{n}$ & $\mathrm{o}$ & $\mathrm{H}$ & Nantes \\
\hline Nutrired & Osbourne Seed & $\mathrm{y}$ & $\mathrm{r}$ & $\mathrm{OP}$ & Imperator \\
\hline Olympus & Sakata & $\mathrm{n}$ & $\mathrm{o}$ & $\mathrm{H}$ & Imperator \\
\hline Paris Market & Annies Heirloom Seeds & $\mathrm{y}$ & $\mathrm{o}$ & $\mathrm{OP}$ & Ball \\
\hline Parisienne & Baker Creek & $\mathrm{y}$ & $\mathrm{o}$ & $\mathrm{OP}$ & Ball \\
\hline Parmex & Kitchen Garden Seeds & $\mathrm{y}$ & $\mathrm{o}$ & $\mathrm{OP}$ & Ball \\
\hline Pot o Gold & Vermont Bean Seed Company & $\mathrm{y}$ & $\mathrm{o}$ & $\mathrm{H}$ & Nantes \\
\hline PrimeCut & Nunhems & $\mathrm{n}$ & $\mathrm{o}$ & $\mathrm{H}$ & Imperator \\
\hline Prodigy & Pinetree Seeds & $\mathrm{y}$ & $\mathrm{o}$ & $\mathrm{OP}$ & Danvers \\
\hline PS07101441 & Seminis & $\mathrm{n}$ & $\mathrm{o}$ & $\mathrm{H}$ & Imperator \\
\hline Purple Haze & Johnny's & $\mathrm{y}$ & $\mathrm{p}$ & $\mathrm{H}$ & Danvers \\
\hline Purple Sun & Kitchen Garden Seeds & $\mathrm{y}$ & $\mathrm{p}$ & $\mathrm{H}$ & Danvers \\
\hline Purplesnax & Osbourne Seed & $\mathrm{y}$ & $\mathrm{p}$ & $\mathrm{H}$ & Imperator \\
\hline Rainbow & Bejo & $\mathrm{n}$ & s & $\mathrm{H}$ & Danvers \\
\hline Red-Cored Chantenay & High Mowing & $\mathrm{y}$ & $\mathrm{o}$ & $\mathrm{OP}$ & Chantenay \\
\hline Red Samurai & Kitchen Garden Seeds & $\mathrm{y}$ & $\mathrm{r}$ & $\mathrm{OP}$ & Danvers \\
\hline Resistafly & Thompson Morgan & $\mathrm{y}$ & $\mathrm{o}$ & $\mathrm{H}$ & Nantes \\
\hline Rodelika & Turtle Tree & $\mathrm{y}$ & $\mathrm{o}$ & $\mathrm{OP}$ & Danvers \\
\hline Rolanka & Turtle Tree & $\mathrm{y}$ & $\mathrm{o}$ & $\mathrm{OP}$ & Danvers \\
\hline Romance & Nunhems & $\mathrm{n}$ & $\mathrm{o}$ & $\mathrm{H}$ & Nantes \\
\hline Rothild & Cooks Garden & $\mathrm{y}$ & $\mathrm{o}$ & $\mathrm{OP}$ & Danvers \\
\hline Rotild & Renee's Garden Seeds & $\mathrm{y}$ & $\mathrm{o}$ & $\mathrm{OP}$ & Danvers \\
\hline Round Romeo & Renee's Garden Seeds & $\mathrm{y}$ & o & $\mathrm{OP}$ & Ball \\
\hline Scarlet Keeper & Fedco & $\mathrm{y}$ & $\mathrm{o}$ & $\mathrm{OP}$ & Danvers \\
\hline Scarlet Nantes & High Mowing & $\mathrm{y}$ & o & $\mathrm{OP}$ & Nantes \\
\hline Sherbert & Nunhems & $\mathrm{n}$ & $\mathrm{y}$ & $\mathrm{H}$ & Imperator \\
\hline Shin Kuroda 5 & Fedco & $\mathrm{y}$ & $\mathrm{O}$ & $\mathrm{OP}$ & Kuroda \\
\hline Short N Sweet & Burpee & $\mathrm{y}$ & $\mathrm{o}$ & $\mathrm{OP}$ & Chantenay \\
\hline SlimCut & Nunhems & $\mathrm{n}$ & $\mathrm{o}$ & $\mathrm{H}$ & Imperator \\
\hline Snow White & Baker Creek & $\mathrm{y}$ & $\mathrm{w}$ & $\mathrm{OP}$ & Danvers \\
\hline Solar Yellow & Sustainable Seed & $\mathrm{y}$ & $\mathrm{y}$ & $\mathrm{OP}$ & Danvers \\
\hline St. Valery & Baker Creek & $\mathrm{y}$ & $\mathrm{o}$ & $\mathrm{OP}$ & Danvers \\
\hline Starica & Renee's Garden Seeds & $\mathrm{y}$ & $\mathrm{O}$ & $\mathrm{OP}$ & Nantes \\
\hline Sugarsnax & Nunhems & $\mathrm{n}$ & $\mathrm{O}$ & $\mathrm{H}$ & Imperator \\
\hline SUN255 & Nunhems & $\mathrm{n}$ & $\mathrm{O}$ & $\mathrm{H}$ & Imperator \\
\hline Sunrise Red & Evergreen Seeds & $\mathrm{y}$ & $\mathrm{r}$ & $\mathrm{H}$ & Imperator \\
\hline Sweet Treat & Burpee & $\mathrm{y}$ & $\mathrm{O}$ & $\mathrm{H}$ & Danvers \\
\hline Sweetness III & Vermont Bean Seed Company & $\mathrm{y}$ & $\mathrm{O}$ & $\mathrm{H}$ & Nantes \\
\hline Tastypeel & Seminis & $\mathrm{n}$ & $\mathrm{O}$ & $\mathrm{H}$ & Imperator \\
\hline Tendersnax & Nunhems & $\mathrm{n}$ & $\mathrm{O}$ & $\mathrm{H}$ & Nantes \\
\hline Tendersweet & Annie's Heirloom Seeds & $\mathrm{y}$ & $\mathrm{o}$ & $\mathrm{OP}$ & Nantes \\
\hline Thumbelina & Kitchen Garden Seeds & $\mathrm{y}$ & $\mathrm{o}$ & $\mathrm{OP}$ & Ball \\
\hline Tokita's Scarlet & Evergreen Seeds & $\mathrm{y}$ & $\mathrm{o}$ & $\mathrm{OP}$ & Kuroda \\
\hline Tonda Di Parigi & Baker Creek & $\mathrm{y}$ & $\mathrm{O}$ & $\mathrm{OP}$ & Ball \\
\hline
\end{tabular}


Table 1. Cont.

\begin{tabular}{cccccc}
\hline Cultivar & Company & FTO & Color & Type & Market Class \\
\hline TopCut & Nunhems & $\mathrm{n}$ & $\mathrm{o}$ & $\mathrm{H}$ & Imperator \\
Touchon & Cooks Garden & $\mathrm{y}$ & $\mathrm{o}$ & OP & Nantes \\
Triple Play & Nunhems & $\mathrm{n}$ & $\mathrm{o}$ & $\mathrm{H}$ & Imperator \\
Triton & Osbourne Seed & $\mathrm{n}$ & $\mathrm{o}$ & $\mathrm{H}$ & Imperator \\
UpperCut & Nunhems & $\mathrm{n}$ & $\mathrm{o}$ & $\mathrm{H}$ & Imperator \\
Vitana & Nunhems & $\mathrm{n}$ & $\mathrm{o}$ & $\mathrm{H}$ & Nantes \\
White Belgian & Baker Creek & $\mathrm{y}$ & $\mathrm{w}$ & OP & Belgian \\
White Kuttiger & Seedrack & $\mathrm{y}$ & $\mathrm{w}$ & OP & Danvers \\
White Satin & High Mowing & $\mathrm{y}$ & $\mathrm{w}$ & $\mathrm{H}$ & Belgian \\
Sovereign & UW-Madison & $\mathrm{y}$ & $\mathrm{o}$ & OP & Chantenay \\
Oranje & UW-Madison & $\mathrm{y}$ & $\mathrm{o}$ & OP & Danvers \\
Yaya & High Mowing & $\mathrm{y}$ & $\mathrm{o}$ & $\mathrm{H}$ & Nantes \\
Yellow Sun & Johnny's & $\mathrm{y}$ & $\mathrm{y}$ & $\mathrm{H}$ & Chantenay \\
Yellow Bunch & Nunhems & $\mathrm{n}$ & $\mathrm{y}$ & $\mathrm{H}$ & Imperator \\
Yellowpak & Nunhems & $\mathrm{n}$ & $\mathrm{y}$ & $\mathrm{H}$ & Imperator \\
Yellowstone & High Mowing & $\mathrm{y}$ & $\mathrm{y}$ & OP & Danvers \\
\hline
\end{tabular}

\section{1. $F_{1}$ Hybrids}

As an outcrossing species with cytoplasmic male-sterility, it is possible to develop both open-pollinated and $\mathrm{F}_{1}$ hybrid cultivars of carrot. Like many outcrossing crops, $\mathrm{F}_{1}$ hybrid cultivars of carrot exhibit heterosis and greater uniformity. $F_{1}$ hybrids are also, in some sense, the original form of IPR used in seed propagated plants. As described earlier, $F_{1}$ hybrids serve as a built-in trade secret for the inbred parent lines, which allows for greater control of the cultivar [3]. Since the 1950's, the majority of carrot breeding programs in the United States have focused on developing inbred lines for $F_{1}$ hybrid cultivar production, utilizing selection of inbred lines from existing open pollinated cultivars [10]. In this collection of commercially available cultivars, 77 of the 140 were $F_{1}$ hybrids. $F_{1}$ hybrid cultivars were the only cultivars with use restrictions. $F_{1}$ hybrids are generally not included in breeding because of the heterogeneous population that results and the incorporation of sterile cytoplasm. We did include $\mathrm{F}_{1}$ hybrids in the populations in order to incorporate the diversity that those cultivars represent.

\subsection{Private Ordering: Contracts and Licenses}

Perhaps the most ambiguous and pervasive type of IPR in carrot is through private ordering, such as legal contracts, licenses and MTAs. These types of agreements overcome some of the limitations of public IPR law and can create more restrictive forms of control over plant genetic resources [20]. Companies, universities, and other organizations are increasingly using contracts, MTAs, and bag-tag licenses to control flow of germplasm.

Some type of contract now accompanies the majority of seed transfers between parties in the U.S. [21-23]. Farmers sign contracts when purchasing seed, essentially leasing seed for use [22]. Breeders sign contracts or MTAs when obtaining seed to use in breeding from the majority of seed sources [24]. Through the process of obtaining seed for this project, we encountered several types of contracts and licenses.

A contract developed between the University of Wisconsin-Madison and a seed company was the most restrictive and explicit mechanism for control that we encountered in this project. This process took nearly six months to finalize and required the expertise of lawyers from both the company and university. The final agreement allowed us to use the cultivars for research (observing phenotype and genotype) but not for breeding or crossing. This was certainly the most explicit form of protection, as a detailed agreement was signed outlining the exact process that would be used.

On the more ambiguous end of the spectrum were the "bag-tag" licenses. These licenses are found on the seed packet and take the form of "shrink wrap" licenses that commonly contain language that restricts breeding, research, seed production, and seed re-sale. Essentially, these licenses amount to a one time "rental" or "lease" on the use of the seed [22]. Licenses are not backed up by public 
law, meaning that if the license is not received with the seed, there is no way to enforce the terms. Additionally, there have not been any court cases based solely on "bag-tag" licenses so it is unclear how they would be viewed in the legal system. Licenses are intended to allow the licensee use of a product for a specific purpose that is owned by the licensor [14]. Licenses are intended for products that have IPR associated with them. Interestingly, none of the carrots that had "bag tag" licenses on their packages actually had any official IPR associated with them, other than being $\mathrm{F}_{1}$ hybrid cultivars. Thus, it is unclear whether these "bag tag" licenses would actually be legally enforceable. Regardless, "bag tag" licenses can certainly have a chilling effect on the use of germplasm for breeding or research. We did not use any material that had a "bag-tag" license since it was unclear exactly what the implications of using this material would be.

\subsection{Utility Patents}

In 2013-2014, 14 utility patents were applied for on new carrot cultivars. This is an increase from the 1 previous utility patent application from 2007, making a total of 15 applications, 9 of which have been granted as of this writing. These 15 patents and patent applications include 13 on carrot cultivars, all of which are $F_{1}$ hybrids in the cut-and-peel market class. While utility patents on specific cultivars do restrict access to those specific cultivars for use in breeding for 20 years, most restrictive might be utility patents on specific traits. In carrot, there is a patent application pending on the specific trait of "Carrot plants with a high anthocyanin level" of at least $2000 \mu \mathrm{g} / \mathrm{g}$ FW [25]. Additionally, a patent on "Carrots having increased lycopene content" [26] was granted in November 2015.

While these patents represent substantial breeding work to increase levels of anthocyanin and lycopene, the accumulation of these compounds in carrot roots is not new. The potential impact of utility patents on future breeding activity of colored carrot populations could be considerable. The patenting process is a give and take between the applicant and the patent examiner [14]. There are elements of objectivity and subjectivity inherent to the system. The applications alone, which are public documents that are accessible during the multi-year process of obtaining a patent, may have a chilling effect on the use of material in plant breeding programs, as uncertainty remains around how trait patents might affect others using similar traits [27]. The specificity of the claims on trait patents could affect the FTO for breeding red or purple carrots in general.

In order for a patent to be granted, the invention must meet the criteria of novel, non-obvious, and useful. The patent applicants must successfully argue that the claims made meet these criteria. This is likely why the claims submitted in the initial application for carrots containing high levels of lycopene were far more general and all-encompassing than the final claims in the granted patent. The plant cultivars that we use in agriculture today are the result of thousands of years of breeding and selection by farmers all over the world. It is therefore less clear how a utility patent can be granted on an "invention" of a plant cultivar or trait that is naturally found in plant germplasm.

\subsection{Plant Variety Protection Certificate}

We recognize that certain forms of IPR, such as PVP, do allow for breeding and so could have been included in a foundation composite population in this project. However, of the 140 commercially available carrot cultivars that were identified for this study, none had a PVP certificate associated with them. Historically, there have only ever been 9 PVP certificates granted on carrot cultivars [28]. Whether this is because $F_{1}$ hybrids have an inherent form of IPR without paying for a PVP certificate, which can cost between $\$ 7500$ and $\$ 10,000$, or that there are now more restrictive ways to control germplasm such as contracts and utility patents, PVP does not appear to be a common mechanism of protection for carrot cultivars.

\subsection{FTO for Plant Breeding Programs}

Generally, cultivars are released in one of two ways. One way is for the developer to claim ownership over the cultivar, the combination of genes or traits that make a cultivar unique, and any 
derivatives developed from that cultivar, and place use restrictions on it through some form of IPR. Alternatively, a cultivar can be released into the public domain, where anyone can have access to it and/or use it in breeding, research or seed saving. However, derivatives of cultivars in the public domain can be appropriated by IPR as long as they meet the appropriate criteria for protection by a given form of IPR. As an alternative to either of these methods, we co-developed the Open Source Seed Initiative (OSSI, www.osseeds.org) and are releasing these populations under the OSSI Pledge. The OSSI Pledge essentially creates a "protected commons" where anyone can gain access as long as they agree that any derivatives of open source material are also pledged as open source, thus having a viral effect and ensuring availability into the future [6]. The Pledge states: "You have the freedom to use these OSSI-Pledged seeds in any way you choose. In return, you pledge not to restrict others' use of these seeds or their derivatives by patents or other means, and to include this pledge with any transfer of these seeds or their derivatives".

The number of public sector plant breeding programs is declining and the majority of resources directed at plant breeding are now in the private sector [16]. Historically, plant breeders shared material with each other and there was exchange between public and private sector programs. It was apparent from conversations with plant breeders throughout the development of the populations, that many would still be willing to share their material for research or breeding purposes. However, legal departments and technology transfer offices at companies and universities are in charge of transfer of plant material and restrictions are often placed on transfer of material. From a breeding perspective, it can be difficult to know what is actually restricted and what has FTO. One of the questions raised throughout this project is whether developing a breeding program in a specific crop is possible, and if so, where does a breeder obtain material if they do not have access to breeding material from a long-standing breeding program? This will be a consideration as public sector positions are no longer filled when current plant breeders retire.

In carrot, there are two university-based public sector plant breeding programs in the United States. Both are located in Madison, WI; one is the USDA-ARS program and the other is the University of Wisconsin-Madison based program. There are also approximately six private sector carrot breeding programs in the United States. Depending on the program, the focus of breeding on market class varies and cultivars are released in different ways. The main focus of most carrot breeding programs in the United States is on the imperator/cut-and-peel market class [10].

On the most accessible end of the spectrum is the USDA program. The USDA-ARS plant breeding programs have a policy that requires cultivars, inbred lines, and breeding populations to be released into the public domain [29]. While this means that germplasm is available for anyone to use when it is released from the USDA program, it does not mean that derivatives of that material remain available. USDA lines can be used in other breeding programs and derivatives can be protected by IPR, potentially restricting further breeding by others. One private sector carrot breeder who was starting a U.S. breeding program in cut-and-peel carrots credited the USDA program with being the source of starting material for his program. The interesting contradiction is that many of the resulting cultivars from this new breeding program will likely be restricted by the company using some form of IPR, thus demonstrating how a public resource can be appropriated under private terms and ownership.

University breeding programs, after the Bayh-Dole act of 1980, may take title to any germplasm developed in whole or in part with federal funds through the technology transfer offices of their university. Cultivars are generally released under some type of license or MTA. While some cultivars and breeding lines have been profitable for universities under this model, with others the system has become so complicated by MTAs that exchange between breeders at different institutions might not occur as a result [24]. The University of Wisconsin-Madison carrot-breeding program first discloses cultivars and inbred lines to the Wisconsin Alumni Research Foundation (WARF), the technology transfer office for the university. This office then determines how cultivars are released. Generally, this is with some type of MTA or license specifying a royalty agreement. It is of interest that plant germplasm is included among the category of "inventions" that universities consider as products 
of their research programs. Land grant universities have historically had a mandate to improve agricultural production through improved cultivars, so it might be argued that the work of plant breeders at public institutions is a service, rather than a source of research inventions. There has been tension in relation to the changes in IPR and technology transfer at universities and whether plant breeding is true research and invention or part discovery.

The industry breeding programs release cultivars in a number of different ways. Some $F_{1}$ hybrid cultivars are sold with no form of IPR protection, as the $\mathrm{F}_{1}$ hybrid serves as a type of trade secret over the inbred parent lines used to produce the $\mathrm{F}_{1}$ hybrid. Others are sold with a bag-tag license or MTA, or are sold or transferred under a contract detailing a specific use agreement.

\subsection{Transfer of Seed}

With the trend towards increasing IPR protection, it is difficult to obtain material directly from a breeder at any institution or company without an accompanying license or contract. Sometimes, this process is so cumbersome that it is easier not to incorporate new material into a breeding program than to deal with the potential legal ramifications. How IPR is actually being enforced and the reality of how seed is transferred and used raises questions about what germplasm actually has FTO for plant breeding.

The source of seed is one of the confounding factors in this situation. Seed can be sold to a large-scale grower or a gardener, or in contrast, released to a different breeding program with the intent of doing research or breeding with a cultivar. Additionally, seed companies with breeding programs license cultivars to seed companies without breeding programs to increase seed to sell. Thus cultivars can be purchased from a variety of sources. However, they do not come with the same restrictions from all sources. In multiple instances, when we obtained the same cultivar from two different sources, one had use restrictions and the other did not. We did not use these cultivars in breeding since it was unclear what FTO we actually had, but the example clearly demonstrates the disconnect. In carrot, the primary way that IPR operates to constrain breeding, besides the obvious contractual restrictions, is through the chilling effect that various IPR protections have over germplasm. The actual constraints on breeding are somewhat vague, but the implication that there are potential constraints can prevent a breeder from using that germplasm. This chilling effect has the potential to create silos of germplasm as exchange between pools becomes limited due to complicated legal agreements and consolidation in the seed industry.

\subsection{The Open Source Seed Initiative (OSSI)}

The Open Source Seed Initiative provides a framework for open-source exchange of germplasm [19]. This means that cultivars and material released through the OSSI Pledge are available to use without restriction as long as derivatives developed using the OSSI-Pledged material also have the same associated FTO.

The WI-OSC carrot populations are intended to be pre-breeding populations representing some of the diversity present in commercially available carrot cultivars. We hope that they will be used in breeding new cultivars and be an example of the potential for open source plant breeding. Since the WI-OSC populations are being released under the OSSI-Pledge, any derivative or cultivar developed using these populations or selected from these populations must also be released under the OSSI-Pledge. OSSI-Pledged cultivars and populations are clearly labeled as OSSI and include the Pledge with transfer of seed. A database of OSSI-Pledged cultivars is maintained on the OSSI website (www.osseeds.org/seeds) and information on parental background is collected upon submission.

There has been substantial interest in OSSI from the organic seed sector. The organic sector has seen rapid growth and is the focus of an increasing number of independent seed companies. As these companies work to develop their own cultivars and work with breeders to add cultivars to their catalogs, the use of the OSSI Pledge is an attractive method of crediting the breeder of a cultivar, allowing access to that cultivar for a variety of purposes, as well as educating consumers about issues 
of access to plant genetic resources. As the organic seed sector continues to develop, which cultivars have FTO for use in breeding and how cultivars are released will be important considerations.

\section{Conclusions}

Crop genetic resources are increasingly protected with IPR. As such, their FTO has become limited for the purpose of plant breeding. Alternatives to the modern IPR regime could enhance future plant breeding efforts. This paper described the process of determining FTO for plant breeding with commercially available carrot germplasm and how that influenced the development of open source crop germplasm. We found that it was difficult to determine which cultivars are protected with IPR and whether a cultivar has FTO for plant breeding. FTO is not always clearly labeled depending on how seed is obtained. These eight open-source carrot populations provide an unrestricted avenue for plant breeding within carrot. The breeding process of these composite populations has elucidated how the complexity of the legal landscape makes determining FTO a complicated process. The release of these populations as OSSI-Pledged ensures that at least some of the diversity currently used in commercially available cultivars remains available with FTO into the future. We hope that these populations will be used in breeding new cultivars of carrot and that they can serve as an example of the potential for open source plant breeding.

Acknowledgments: We thank Steve Pincus and Beth Kazmar of Tipi Produce, Evansville, Wisconsin, and Eric Elderbrock of Elderberry Hill Farm, Waunakee, Wisconsin for their collaboration in the field production of carrots used in this work. We thank the Clif Bar Family Foundation and the Seed Matters initiative for a Seed Matters Fellowship in Organic Plant Breeding to Claire H. Luby. We also thank NC-SARE and the Ceres Trust for partial support of this project.

Author Contributions: Claire H. Luby and Irwin L. Goldman conceived and designed the project. Claire H. Luby performed the experiments, conducted the analysis, and wrote the paper. Both authors contributed perspectives and sections to the Results and Discussion section.

Conflicts of Interest: The authors, in addition to being university researchers, are both members of the board of the Open Source Seed Initiative. The funding sponsors had no role in the design of the study; in the collection, analyses, or interpretation of data; in the writing of the manuscript, and in the decision to publish the results.

\section{References}

1. Coffman, W.R.; Lesser, W.H.; McCouch, S.R. Commercialization and the Scientific Research Process: The Example of Plant Breeding; Stephan, P.E., Ehrenburg, R.G., Eds.; Science and the University, University of Wisconsin Press: Madison, WI, USA, 2003.

2. Graf, G.; Cullen, S.; Bradford, K.; Zilberman, D.; Bennet, A.B. The public-private structure of intellectual property ownership in agricultural biotechnology. Nat. Biotechnol. 2003, 21, 989-995. [CrossRef] [PubMed]

3. Kloppenburg, J. First the Seed: The Political Economy of Plant Biotechnology, 1492-2000, 2nd ed.; University of Wisconsin Press: Madison, WI, USA, 2004.

4. Louwaars, N.; Dons, H.; Van Overwalle, G.; Raven, H.; Arundel, A.; Eaton, D.; Nelis, A. Breeding Business: The Future of Plant Breeding in the Light of Developments in Patent Rights and Plant Breeder's Rights; Center for Genetic Resources Report: Wageningen, The Netherlands, 2009.

5. Price, S.C. Public and private plant breeding. Nat. Biotechnol. 2009, 17. [CrossRef]

6. Luby, C.H.; Kloppenburg, J.; Michaels, T.M.; Goldman, I.L. Enhancing freedom to operate for plant breeders and farmers through open source plant breeding. Crop Sci. 2015, 55, 2481-2488. [CrossRef]

7. USDA. National Agricultural Statistics Service, Data and Statistics (Vegetables). Available online: http: //www.nass.usda.gov/Statistics_by_Subject/ (accessed on 13 July 2015).

8. Stolarczyk, J.; Janick, J. Carrot: History and iconography. Chron. Hortic. 2011, 51, 13-18.

9. Brothwell, D.R.; Brothwell, P. Food in Antiquity: A Survey of the Diet of Early Peoples; Thames \& Hudson: London, UK, 1969.

10. Simon, P.W. Domestication, historical development, and modern breeding of carrot. Plant Breed. Rev. 2000, 19, 157-190.

11. Umiel, N.; Gabelman, W.H. Analytical procedures for detecting carotenoids of carrot (Daucus carota L.) roots and tomato (Lycopersicum esculentum) fruits. J. Am. Soc. Hortic. Sci. 1971, 96, 702-704. 
12. Umiel, N.; Gabelman, W.H. Inheritance of root color and carotenoid synthesis in carrot Daucus carota L.: Orange vs. red. J. Am. Soc. Hortic. Sci. 1972, 97, 453-460.

13. Aoki, K. Seeds of Dispute: Intellectual property rights and agricultural biodiversity. Gold. Gate Univ. Environ. Law J. 2009, 3, 79-160.

14. Jondle, R.J.; Hill, K.K.; Sanny, T. Current legal issues in intellectual property rights and protection for crop plants. Crop Sci. 2015, 55, 2496-2503. [CrossRef]

15. Pardey, P.; Koo, B.; Drew, J.; Horwich, J.; Nottenburg, C. The evolving landscape of plant varietal rights in the United States, 1930-2008. Nat. Biotechnol. 2013, 31, 25-29. [CrossRef] [PubMed]

16. Murphy, D. Plant Breeding and Biotechnology; Cambridge University Press: Cambridge, UK, 2007.

17. J.E.M. Ag Supply Inc., v. Pioneer Hi-Bred Int'l, Inc.; 534 U.S. 124, 127 (2001). Available online: https: //supreme.justia.com/cases/federal/us/534/124/case.html (accessed on 12 May 2016).

18. Ex Parte Hibberd. 227 U.S.P.Q. (BNA) 443 (Bd. Pat. App. And interferences 1985). Available online: https://www.justice.gov/osg/brief/jem-ag-supply-inc-v-pioneer-hi-bred-intl-inc-amicus-merits (accessed on 12 May 2016).

19. Luby, C.H.; Goldman, I.L. Release of eight open source carrot (Daucus carota L. var. sativus) composite populations developed under organic conditions. HortScience 2016, 51, 1-3.

20. Dusollier, S. Sharing access to intellectual property through private ordering. Chic. Kent Law Rev. 2007, 82, 1391-1435.

21. Heimes, R.S. Post-sale restrictions on patented seeds: Which law governs? Wake For. Intellect. Prop. Law J. 2010, 10, 98-152.

22. Kloppenburg, J. Re-purposing the master's tools. In Food Sovereignty: A Critical Dialogue, Proceedings of the Food Sovereignty: A critical dialogue, International Conference, Yale University, New Haven, CT, USA, 14-15 September 2013.

23. Winston, E. What if seeds were not patentable? Mich. State Law Rev. 2008, 2008, 321-344.

24. Bennett, A.B.; Streitz, W.D.; Gacel, R.A. Intellectual Property Management in Health and Agricultural Innovation: A Handbook of Best Practices; Krattiger, A., Mahoney, R.T., Nelsen, L., Thomson, J.A., Bennett, A.B., Satyanarayana, K., Graff, G.D., Fernandez, C., Kowalski, S.P., Eds.; MIHR: Oxford, UK; PIPRA: Davis, CA, USA, 2007; Available online: http://www.iphandbook.org (accessed on 12 May 2016).

25. Freeman, R. Carrot Plants with a High Anthocyanin Level. U.S. Patent Application 20140245471, 28 August 2014.

26. Maxwell, R. Carrots Having Increased Lycopene Content. U.S. Patent U.S.9173355B2, 3 November 2015.

27. Hamilton, L. Linux for lettuce. Available online: http://www.vqronline.org/reporting-articles/2014/05/ linux-lettuce (accessed on 10 February 2016).

28. USDA. Agricultural Marketing Service, PVPO Scanned Certificates Database. Available online: http: / /apps.ams.usda.gov/CMS/ (accessed on 13 July 2015).

29. Agricultural Research Service. Technology Transfer Handbook for ARS Plant Breeders. Available online: http:/ / www.ars.usda.gov/SP2UserFiles/Place/00000000/OTTGeneral/ARSPlantBreedersHandbook.pdf (accessed on 10 February 2016).

(C) 2016 by the authors; licensee MDPI, Basel, Switzerland. This article is an open access article distributed under the terms and conditions of the Creative Commons Attribution (CC-BY) license (http:/ / creativecommons.org/licenses/by/4.0/). 